\title{
Experiences of Nursing/Midwifery Students on Clinical Learning Processes in a Training Hospital in Northern Nigeria
}

\author{
Yahaya Jafaru (iD) 1, ${ }^{*}$, Muhammed Murtala Musa ${ }^{2}$ and Gaddafi Wasagu Sani ${ }^{2}$ \\ ${ }^{1}$ Department of Nursing Science, College of Health Sciences, Federal University Birnin-Kebbi, Kebbi State, Nigeria \\ ${ }^{2}$ School of Nursing and Midwifery Birnin-Kebbi, Kebbi State, Nigeria \\ "Corresponding author: Department of Nursing Science, College of Health Sciences, Federal University Birnin-Kebbi, Kebbi State, Nigeria. Email: jafaruyahaya2015@yahoo.com
}

Received 2021 March 13; Revised 2021 December 14; Accepted 2022 January 26.

\begin{abstract}
Background: The study aimed to explore the nursing/midwifery students' experiences of clinical learning processes in Kebbi State Training hospital.

Methods: A qualitative cross-sectional descriptive design was adopted using a phenomenological approach. The study population included the second and third-year nursing/midwifery students of the School of Nursing and Midwifery Birnin-Kebbi, Kebbi State, Nigeria. Twenty students were purposively selected to participate in individual interviews for data collection.

Results: The results were characterized by mixed reactions and experiences from different respondents. The emerged themes were students' supervision, students' encouragement, communication with students, respecting students, students' learning support, and ethical practice. The respondents' experiences mainly were both positive and negative.

Conclusions: Nurses and midwives need to put more effort into clinical learning and training of nursing and midwifery students for professional development. Clinical teaching and professionalism should be part of staff nurses' and midwives' conferences and mandatory continuous development programs.
\end{abstract}

Keywords: Training, Nursing/Midwifery Students, Nurses/Midwives, Experiences, Clinical Learning

\section{Background}

Providing effective nursing and midwifery education is a cost-effective strategy for improving the healthcare workforce and enhancing the quality of healthcare systems (1). Nursing and midwifery education is made up of inseparable theoretical and practical knowledge with the primary goal of developing competent practice (Sundstrom, cited in (2)). This goal is only achievable by enough students' clinical learning opportunities. Ahmadi (3) asserted that midwifery students should be given opportunity in the clinical environment to develop professional clinical skills for professional practice. Clinical learning environment provides students the opportunities to relate theory to practice, develop technical and interpersonal skills, make clinical judgments, and incorporate professional values and ethics (2). Jamshidi et al. (4) asserted that clinical environment in nursing education can influence nursing students in considering nursing as their profession to practice.

Clinical education is the healthcare education conducted in healthcare facilities, outpatient clinics, emergency centers, hospitals, or private offices under the super- vision of a qualified practitioner or teaching staff (5). In clinical learning, students can be considered as part of the workforce, bringing other constructs of work-based learning or work-integrated learning (6). Clinical environment is complex (4) with a lot of psychological and sociological factors that influence learning. According to Ohaja (7), it constitutes the most significant influence on the students' learning process. Nursing students are vulnerable to stressors of the clinical learning environment, which reduces their clinical training satisfaction (8).

Studies have repeatedly showed the nursing students' unsatisfactory experiences of clinical area (9). Begley (10) found that midwifery students acquire clinical knowledge and experience more from senior students and the newly qualified midwives than from experienced senior midwives, and getting the work done is more emphasized than students' learning processes. Some of the reasons for negative experiences include not meeting the students' expectations, frustrations due to poor integration of knowledge, and the lack of tutorial supports (Lipinge \& Venter, cited in (9)). Literature showed that students' experiences can affect the quality of nursing and midwifery students' train-

Copyright (c) 2022, Journal of Medical Education. This is an open-access article distributed under the terms of the Creative Commons Attribution-NonCommercial 4.0 International License (http://creativecommons.org/licenses/by-nc/4.0/) which permits copy and redistribute the material just in noncommercial usages, provided the original work is properly cited. 
ing (11). So, increasing their experience acquisition process is necessary (12).

The nature of clinical experience determines the quality of nursing educational program (13). This makes investigating clinical learning experiences of nursing and midwifery students to receive international attention $(14,15)$.

\section{Objectives}

This study aimed to evaluate the nursing and midwifery students' clinical learning processes in Kebbi state's training hospital in Nigeria, since there is no research in this field so far. Understanding students' learning processes would pave way to effective clinical competences to students (3).

\section{Methods}

The research used qualitative cross-sectional descriptive design using phenomenological approach. The population of the study was second- and third-year nursing and midwifery students in the School of Nursing and Midwifery Birnin-kebbi. Maximum variation sampling and stratified random sampling were used to select the samples. A maximum variation sampling is done when key dimensions of variations are identified; then the samples that vary from each other as much as possible are drawn (16). It allows a wide range of individuals, groups, or settings to be purposively selected (17). Stratified random sampling is a sampling method whereby the population is divided into sub-populations that make each subpopulation relatively homogeneous and relatively heterogeneous from members of all other sub-groups (17). Thus, to achieve a wide range of individual respondents based on their variations, the respondents of this study were stratified into years of study (year 2 and year 3 ) and grouped into schools (Nursing and Midwifery schools).

To maintain maximum variation sampling, 20 students were purposively and randomly selected based on the strata and groups. It was done by obtaining sampling frame and selecting five students from each year in the two schools. The participants from the Nursing School constituted five males and five females, but all the midwifery students were female. Individual interview was conducted to collect the data. Although signs of data saturation began to manifest after 17 interviews, all the 20 respondents were interviewed. All subjects participated in the research voluntarily, and their information was treated with utmost anonymity. To reinforce anonymity, the number given to each respondent in the results of the study does not represent the sequence by which they attended the interview.
Ethical approval was obtained from the Kebbi State Health Research Ethical Committee (code: 104:8/2018). Permissions to conduct the research were also obtained from the schools and the hospital.

\subsection{Study Setting}

The study was conducted in Sir Yahaya Memorial Hospital Birnin-Kebbi, Kebbi State, Nigeria. The hospital is the most visited and biggest hospital in Kebbi State, Nigeria. It was built in 1951 as a cottage hospital. Over the years it grew to become a general hospital before its current status as a 250-bed specialist hospital (18). The hospital provides services in surgery, pediatrics, obstetrics and gynecology, ophthalmology, dentistry, radiology, physiotherapy, and dermatology with modern facilities, infrastructure, and equipment. It has 13 wards, one hospital store, X-ray machine, mammography machine, two ultrasound machines, six dialysis machines, three ambulances, and one call duty vehicle (19).

\subsection{Data Collection and Analysis}

Phenomenological individual interview was used for data collection. Phenomenology involves re-examining the experiences commonly taken for granted, leading to the emergence of abandoned ideas (20). The purpose of phenomenology is to describe phenomena of interest and the appearance of situations as lived experience (21). In descriptive phenomenology, the researcher analyzes the descriptions given by participants and divides them into meaning-laden statements. The essential meanings are gathered to construct the phenomena under study and develop a written description of the structure of the phenomenon of interest (22).

In this study, the Giorgi's descriptive phenomenological method was used. In this method, the researcher conducts interviews with the participants, transcribes the interview verbatim, and reads the entire transcription. The researcher assumes the attitude of the scientific phenomenological reduction and creates parts by delineating psychological meaning units. The researcher intuits and transforms the participants' life world expressions into expressions that highlight the psychological meanings lived by participants. The researcher uses the transformed meaning unit expressions as the basis for describing the psychological structure of the experience (23).

Bracketing was also applied to avoid the influence of any preconceived ideas on part of the researchers. Reflexivity was applied throughout the research process, from literature to conducting the interview, data analysis, and results presentation. This was done by using a reflexive diary in which the researchers' thoughts, feelings, and perceptions about the phenomena of interest were identified and 
controlled throughout the research process. During the interviews, additional insights were demanded from the participants to clarify the meanings of the responses and to ascertain the connections between experiences. This results in deeper insight into the participants' responses and prevents the researchers' presuppositions, preconceptions, and experiences from influencing or misinterpreting the results.

The time range of interviews was 9 - 20 minutes depending on how the respondents provided detailed information, and it involved questioning reflection, and clarification. The interview was audio-recorded, and the researchers listened to the audio over and over and transcribed it verbatim. The meaning units were identified using the literal content, non-verbal cues, and deeper insight of the participants' responses. For instance, the terms 'taught' and 'show' were found to mean supervision. This led to regrouping meaning units into clusters that were relevant and coherent. The terms 'taught' and 'show', as well as the phrases 'They will be relaxing allowing students to carryout procedures...' and 'They won't even follow you and see what you are doing...' were clustered under the theme 'students supervision'. This was followed by coherent organizations of the participants' experiences in each theme; also, similarities and differences were established. For example, participants that experienced supervision and those that did not experience it were identified and organized logically. The transcribed data were given to the participants individually to ascertain the appropriateness of the responses. The participants confirmed that the results of the analysis were their intended opinions. Content analysis was used to describe and interpret the data. To be more conversant with the data, the researchers read the transcribed data several times. After vigorous considerations, the data were coded, and themes emerged from the coded data. Data were then analyzed and described based on the emerged themes.

\subsection{Trustworthiness Strategies of the Study}

The best criteria known for ensuring trustworthiness in qualitative research are credibility, transferability, dependability, and confirmability $(24,25)$. In this study, the trustworthiness of the study was ensured by maintaining credibility through applying appropriate research methods, random sampling in selecting the participants units, voluntary participation of the respondents, peer scrutiny of the research, and ensuring correct interpretation of the participants' original views. The researchers facilitated the transferability judgment by a potential user through thick description. That is describing experiences and their context to become meaningful to an outsider. The participants evaluated the findings, interpretations, and recommendations of the study and confirmed that they were in agreement with the information given (dependability). Also, data and interpretations of the findings were clearly derived from the study process (confirmability).

\section{Results}

Out of 20 participants, $75 \%$ were females and $25 \%$ were males. Also, $40 \%$ were in the age range of 18 - 21 years, another $40 \%$ in the age range of $22-25$ years, $10 \%$ in the age range of $26-29$ years, and another $10 \%$ in the age range of $\geq$ 30 years. In addition, the respondents were selected from each year in two schools.

The results of the study are characterized by mixed reactions and experiences from different respondents. The varying aspects of the data are presented according to the emerged themes.

\subsection{Students' Supervision}

Some respondents indicated satisfactory provision of students' supervision by staff nurses and midwives. Respondent 4 pointed out “...they used to supervise students so that the student will not make mistake". Respondent 18 stated that "...if she wants to perform a procedure, she will call and teach us...." "I said I am afraid of injuring the patient, but he said come and try it. I will show you how to do it" (respondent 5).

Other respondents experienced lack of supervision from the staff nurses/midwives. "A staff would say a student come and do this, and without supervision" (respondent 5). Also, respondent 7 stated that "Sometimes they used to send students to undergo some certain procedures without close supervision...”. Another experience showed lack of conversance with the students. "She just called a new student... and he just went and diluted with lidocaine and started giving to the patient intravenously... that is lack of supervision" (respondent 5).

Lack of nurses' commitment to the work and students' training was evident from the data. "They will be relaxing allowing students to carryout procedures..." (respondent 10). Respondent 12 attested that "They won't even follow you and see what you are doing... you just go and just give them any wrong information and they will accept".

Another experience showed the existence of supervision from staff nurses/midwives at the initial stage of the students' clinical posting. "The first two weeks of our posting were very-very busy... but later, they just left us... (respondent 9). Respondent 1 confirmed that “... they will be supervising us like the first time we came to the hospital.... but if we take like one week, the nurses will not bother to 
supervise”. Respondent 19 mentioned that “... they will not teach you except if it is first posting".

Restricting students from practicing a procedure was evident in the results. "... like MVA (Manual Vacuum Aspiration), some nurses will not allow students to carry out MVA... and it is annoying" (respondent 1). Most of the respondents expressed that clinical learning processes were unsatisfactory in terms of supervision.

\subsection{Students' Encouragement}

According to the respondents' experiences, staff nurses and midwives encouraged the students. Respondent 7 attested that "I have been experiencing encouragement". Respondent 2 stated that “... and also encourage you to read more..."

Respondent 16 narrated how a nurse encouraged: “... You can do it; try it! Stop telling you don't know how to do it". Respondent 17 mentioned that: "I get that encouragement in ANC from the matron. She said you can do it. She guided me on how to do the procedure, and she stayed there to supervise me. I felt very happy that day".

However, respondent 14 indicated an average level of students' encouragement by the staff nurses. "They don't usually encourage us... only few of them called students to encourage them".

\subsection{Communication with the Students}

There was a mixed experience regarding the way staff nurses and midwives communicated with the students.

"The communication is clear and understandable" (respondent 7); "it is understandable" (respondent 4); "clear statement in a soft word" (respondent 16); "is in soft way, some is clear" (respondent 17); and "it is in soft way but not clear" (respondent 19). Respondent 13 perceived it as "majority of them used soft words in communication".

Other students had different experiences. Respondent 2 perceived it as "seriously violent... as if you are fighting with them ..."; “... even your parents at home will not order you that way..." (respondent 8). Respondent 10 mentioned that "the majority of them shout in giving command". “...some of them will talk to you in a harsh way..." (respondent 13). Respondent 1 explained it this way: “... they don't use a good method; yes, I can say the method of teaching students..."

\subsection{Respecting Students}

The respondents' experiences were dominated with lack of respect to students by staff nurses and midwives. Although some of the respondents experienced respect, "there is respect, and some do respect students" (respondent 1). The respondent 15 stateed: “yes, they used to call us by our names; they don't shout", and respondent 20 said: “... they used to appreciate when we did something good".

Other respondents showed their experiences regarding the lack of respect. "The staff are not respecting the students... they normally treat us like ward servants" (respondent 2); "Seriously Sir, the staff are not respecting the students... they will just take students as nothing" (respondent 4). Respondent 1 highlighted "they say if you are a student, you are nothing..."; "They will shout at students: come here, can't you run!" (respondent 14). Respondent 19 pointed that "They don't take students as anything...." Respondent 13 emphasized "The way they will address you is sometimes very bad". However, respondent 17 stated that “... when we greeted her, she did not answer... she just shouted at us... we felt embarrassed".

\subsection{Students' Learning Support}

There are different experiences from the respondents on the learning supports they get from staff nurses and midwives; some with positive experiences and others with negative experiences. Respondent 2 mentioned that "they will teach... if you ask them question”; “... they teach you, they support you ... some of them are very good, I am telling you the truth they are very good" (respondent 7). Respondent 15 pointed that “... they used to teach us very well... we ask them, and they give us the answer"; “... They conduct a presentation... especially in ANC... the matron in ANC did good things... (respondent 17). Respondent 20 mentioned that: “... they will be supervising you, teaching you..."

Other respondents experienced a lack of learning support from the staff nurses and midwives. "Just few of them normally teach us” (respondent 6); “... some staff won't answer you, even if you have question” (respondent 14). Respondent 2 asserted that: "If you don't ask them, they will not tell you anything... they will quarrel". Another respondent said: “... sometimes they will assign the same students to go and see what the patient manifested" (respondent 4). Respondent 12 stated that: “...if you ask some of them, they will just say you should look it for yourself...”. Respondent 16 said: "... and some of them will be running away to teach the younger ones..."; "They don't normally like to teach us; they don't normally support us..." (respondent 17). Respondent 18 expressed: "They are telling us that we are going to know it, it is not our time; we are going to know it later...", and respondent 20 said: "some of them don't even want us to ask them questions...”. "Most of the times when you ask them questions, they are lazy to answer... it is just God that is helping us..." (respondent 8). 


\subsection{An Aspect of Ethical Practice}

According to the respondents, there were a lot of unethical practices happening in their training. "They will try to tell you to do some maneuver to make that procedure fast. Some don't usually put on gloves, in a hurry way, they will just use it and do it sharp-sharp" (respondent 14). Respondent 7 said that: "sometimes the procedures we used to do were not done ideally..."; "Sometimes the procedures are not carried out as ideal..." (respondent 9).

Another unethical practice was leaving the ward and asking the students to manage everything. "He left us in the ward to call somebody... I was the one that did nurses note, even reports; I was the one that wrote the report..." (respondent 10). Respondent 2 stated that: “... the staff nurse left the nurses' station and she did not come back until I finished serving the medication... at that time, I was in first year"; "... I attended all the evening and night shifts; it was only students that were running the shifts" (respondent 12); "The way they leave the ward for us, most especially during night shift... She told us that her husband is back, she doesn't have time and she will not come" (respondent 14).

Other respondents attested that the staff shouted at students. Respondent 14 stated: "the staff will be shouting at you if you make a slight mistake"; “... I said we are new students, I don't know how to do it. He just started shouting at me in front of the patients and my colleagues..." (respondent 5); "sometimes most of our staff used to quarrel with a student in front of the patients' relatives" (respondent 2). Respondent 16 said that: “... this nurse shouted at me: 'that is not the way you should do it. In fact, move away and let me do it'. I felt bad inside me”; “...they can shout at you in front of patient's relatives... and the patient can lose confidence on you (respondent 17).

Some respondents mentioned that the staff sent them to purchase materials. Respondent 2 mentioned that: “... they send us to the market, as if we are ward servants... we had to go and buy something for her breakfast; something of that nature". Respondent 17 asserted that: "...they used to send us to buy things for them". Respondent 18 said: "...they used to ask students to go and buy meat for them. In uniform! They asked a student to go and buy meat for them! They even asked us to help their babies sleep! And go buy me "Rama" or "Bula" (local food); this is not good".

\section{Discussion}

In this study, the respondents expressed both positive and negative experiences. Usually, nursing and midwifery students experience both negative and positive circumstances in the clinical environment (26). Few respondents had positive experience regarding the students' supervision by staff nurses and midwives. Others experienced a lack of supervision or restricting students from practicing some procedures. In this case, therefore students will find it difficult to learn and develop competences and skills. This finding is consistent with the findings of a research by Ohaja (7) that evaluated the support of learning in clinical area among post-registration midwifery students; the respondents experienced lack of supervision from skilled and experienced individuals.

The majority of the respondents experienced encouragement from the staff nurses and midwives and most of them attested that the encouragement was high. Only few respondents experienced moderate encouragement. This shows a high level of motivation for students to strive and learn the necessary knowledge for nursing practice, which is an essential aspect of students' training. This is contrary to the findings by Mabuda et al. (9), reporting that student nurses spent most of their time in clinical area doing menial tasks. Some respondents had positive experiences regarding communication with staff nurses and midwives. However, some argued that the communication of staff nurses and midwives was terrible. According to Helgesen et al. (27), poor communication and information failure were stressed as leading to interference with students' understanding in the clinical area.

Only few students experienced respect from staff nurses and midwives. This shows a poor method of handling student nurses/midwives in clinical settings, as well as a poor professionalism. Due to the shortage of positive role model, provision of best caring approach to the students is not possible (28). Since student nurses/midwives are potential members and the hope of the professional development, they need to be handled with respect. This is in accordance with findings from Khajehei et al. (29), stating that the nature of clinical setting and midwives themselves can pose a condition stressful to midwifery students. According to Anthony and Yastik (30), negative attitudes of the clinical nurses and poor support of students deter effective learning process.

In the area of students' learning support, the majority of respondents experienced dissatisfaction. This is in accordance with the study by Ohaja (7), in which all the respondents stressed the need for support. Some of the respondents of this research experienced learning supports only when they asked questions, and some others experienced learning support in organizing presentations. This indicates lack of commitment by the staff nurse and midwives in teaching the theoretical knowledge to the students, as part of their learning experiences. Mabuda et al. (9) found that ward staff (registered nurses) were not teaching student nurses. The findings of a study in Eng- 
land showed that strong support is important in acquiring knowledge and skills while practicing (31).

Regarding ethical practices, nearly all the experiences were negative, including leaving the ward for students alone to manage, shouting at the students, and sending the students to the market for purchasing some personal items. These misconducts do not help the students and deter the professional development. Contrary to the respondents' experiences, clinical environment involves appreciation and support from clinical staff, quality of clinical practice, as well as self-directed learning with students' awareness of their limitations, potential and responsibility (32).

\subsection{Conclusions}

The results of this research showed that nurses and midwives should help nursing and midwifery students in clinical settings to improve their professional development. This includes students' supervision, effective communication, good interpersonal relationship with the students, and making sure that student nurses and midwives learn appropriate skills, knowledge, and ethical practice. In this way, knowledge, competences, ethics, culture, and attitude of nursing profession will be transmitted from generation to generation. This role rests entirely on the shoulders of practicing nurses, nurse administrators, and nurse educators. It is therefore important for nurses and midwives to make sure that training and clinical teaching is inculcated into their routine duties, even with work overload and shortage of manpower. There are needs for scrutinizing factors that hinder or enhance clinical learning process of student nurses/midwives. Studies on what makes some staff nurses/midwives involve deeply in student training and learning while others do not are also pertinent.

\section{Footnotes}

Authors' Contribution: Jafaru, Y., Musa, M.M. \& Sani G. W. participated together immensely in formulation of the research topic, literature review, development of proposal, conducting the interview data analysis, and discussion and conclusion.

Conflict of Interests: No conflict of interest was declared by authors.

Data Reproducibility: The data presented in this study are openly available in one of the repositories or will be available on request from the corresponding author by this journal representative at any time during submission or after publication. Otherwise, all consequences of possible withdrawal or future retraction will be with the corresponding author.
Ethical Approval: Ethical Approval Number: 104: 8/2018. Funding/Support: Not declared by authors.

Informed Consent: Written informed consent was obtained from all participants.

\section{References}

1. Bvumbwe T, Mtshali N. Nursing education challenges and solutions in Sub Saharan Africa: an integrative review. BMC Nurs. 2018;17:3. doi: 10.1186/s12912-018-0272-4. [PubMed: 29434521]. [PubMed Central: PMC5793415].

2. Rafiee G, Moattari M, Nikbakht AN, Kojuri J, Mousavinasab M. Problems and challenges of nursing students' clinical evaluation: A qualitative study. J Nurs Midwifery Res. 2014;19(1):41-9.

3. Ahmadi G, Shahriari M, Keyvanara M, Kohan S. Midwifery students' experiences of learning clinical skills in Iran: a qualitative study. Int J Med Educ. 2018;9:64-71. doi: 10.5116/ijme.5a88.0344. [PubMed: 29537968]. [PubMed Central: PMC5951782].

4. Jamshidi N, Molazem Z, Sharif F, Torabizadeh C, Najafi Kalyani M. The Challenges of Nursing Students in the Clinical Learning Environment: A Qualitative Study. Sci World J. 2016;2016:1846178. doi: 10.1155/2016/1846178. [PubMed: 27366787]. [PubMed Central: PMC4913003].

5. Cantatore F, Crane L, Wilmoth D. Defining Clinical Education: Parallels in Practice. Aust J Clin Educ. 2016. doi: 10.53300/001c.5087.

6. Jackson D. Employability skill development in work-integrated learning: Barriers and best practice. Stud High Educ. 2015;40(2):350-67.

7. Ohaja M. Support for learning in the clinical area: the experience of post-registration student midwives. All Ireland J High Educ. 2010;2(1):14.

8. Dehghan Nayeri N, Nazari AA, Salsali M, Ahmadi F, Adib Hajbaghery M. Iranian staff nurses' views of their productivity and management factors improving and impeding it: a qualitative study. Nurs Health Sci. 2006;8(1):51-6. doi: 10.1111/j.1442-2018.2006.00254.x. [PubMed: 16451429].

9. Mabuda BT, Potgieter E, Alberts UU. Student nurses' experiences during clinical practice in the Limpopo Province. Curationis. 2008;31(1):19-27. doi: 10.4102/curationis.v31i1.901. [PubMed: 18592945].

10. Begley CM. 'Great fleas have little fleas': Irish student midwives' views of the hierarchy in midwifery. J Adv Nurs. 2002;38(3):310-7. doi: 10.1046/j.1365-2648.2002.02181.x. [PubMed: 11972672].

11. Salamonson Y, Everett B, Halcomb E, Hutchinson M, Jackson D, Mannix J, et al. Unravelling the complexities of nursing students' feedback on the clinical learning environment: a mixed methods approach. Nurse Educ Today. 2015;35(1):206-11. doi: 10.1016/j.nedt.2014.08.005. [PubMed: 25200510].

12. Houghton CE. 'Newcomer adaptation': a lens through which to understand how nursing students fit in with the real world of practice. J Clin Nurs. 2014;23(15-16):2367-75. doi:10.1111/jocn.12451. [PubMed: 24455974]. [PubMed Central: PMC4263159].

13. Henderson A, Twentyman M, Heel A, Lloyd B. Students' perception of the psycho-social clinical learning environment: an evaluation of placement models. Nurse Educ Today. 2006;26(7):564-71. doi: 10.1016/j.nedt.2006.01.012. [PubMed:16675069].

14. McIntosh T, Fraser DM, Stephen N, Avis M. Final year students' perceptions of learning to be a midwife in six British universities. Nurse Educ Today. 2013;33(10):1179-83. doi: 10.1016/j.nedt.2012.05.020. [PubMed: 22703835].

15. Lake S, McInnes RJ. Exploring cognitive skill development in midwifery education. Nurse Educ Pract. 2012;12(5):264-8. doi: 10.1016/j.nepr.2012.04.015. [PubMed: 22683107]. 
16. Suri H. Purposeful Sampling in Qualitative Research Synthesis. Qual Res J. 2011;11(2):63-75. doi: 10.3316/qrj1102063.

17. Omona J. Sampling in Qualitative Research: Improving the Quality of Research Outcomes in Higher Education. Makerere J High Educ. 2013;4(2):169-85. doi: 10.4314/majohe.v4i2.4.

18. Daily Trust. Kebbi 250-Bed Specialist Hospital Needs Surgical Operation. Daily Trust; 2017. Available from: https://dailytrust.com/kebbi-250bed-specialist-hospital-needs-surgical-operation.

19. Jimeds. Sir Yahaya Memorial Hospital. Jimeds; 2021. Available from: https://jimeds.ng/clinic/sir-yahaya-memorial-hospital.

20. Laverty SM. Hermeneutic Phenomenology and Phenomenology: A Comparison of Historical and Methodological Considerations. Int $J$ Qual Methods. 2016;2(3):127. doi: 10.1177/160940690300200303.

21. Speziale HS, Streubert HJ, Carpenter DR. Qualitative research in nursing: Advancing the humanistic imperative. 4th ed. Philadelphia, USA: Lippincott Williams \& Wilkins; 2007.

22. Penner JL, McClement SE. Using Phenomenology to Examine the Experiences of Family Caregivers of Patients with Advanced Head and Neck Cancer: Reflections of a Novice Researcher. Int J Qual Methods. 2008;7(2):92-101. doi: 10.1177/160940690800700206.

23. Giorgi A, Giorgi B, Morley J. The Descriptive Phenomenological Psychological Method. The SAGE Handbook of Qualitative Research in Psychology. SAGE Publications; 2017. p. 176-92. doi: 10.4135/9781526405555.n11.

24. Shenton AK. Strategies for ensuring trustworthiness in qualitative research projects. Educ Inf. 2004;22(2):63-75. doi: 10.3233/efi-2004-22201.

25. Korstjens I, Moser A. Series: Practical guidance to qualitative research.
Part 4: Trustworthiness and publishing. EurJ Gen Pract. 2018;24(1):1204. doi: 10.1080/13814788.2017.1375092. [PubMed: 29202616]. [PubMed Central: PMC8816392].

26. Atakro CA, Gross J. Preceptorship versus Clinical Teaching Partnership: Literature Review and Recommendations for Implementation in Ghana. Adv Nurs. 2016;2016:1-5. doi: 10.1155/2016/1919246.

27. Helgesen AK, Gregersen AG, Roos AK. Nurse students' experiences with clinical placement in outpatient unit - a qualitative study. $B M C$ Nurs. 2016;15:49. doi: 10.1186/s12912-016-0167-1. [PubMed: 27507927]. [PubMed Central: PMC4977823].

28. Pearcey PA, Elliott BE. Student impressions of clinical nursing. Nurse Educ Today. 2004;24(5):382-7. doi: 10.1016/j.nedt.2004.03.007. [PubMed: 15245861].

29. Khajehei M, Ziyadlou S, Hadzic M, Kashefi F. The genesis and consequences of stress among midwifery students. Br J Midwifery. 2011;19(6):379-85. doi: 10.12968/bjom.2011.19.6.379.

30. Anthony M, Yastik J. Nursing students' experiences with incivility in clinical education. $J$ Nurs Educ. 2011;50(3):140-4. doi: 10.3928/01484834-20110131-04. [PubMed: 21323254].

31. Longworth MK. An exploration of the perceived factors that affect the learning and transfer of skills taught to student midwives. Midwifery. 2013;29(8):831-7. doi: 10.1016/j.midw.2012.07.013. [PubMed: 23079869].

32. Dalton L. Use of clinical space as an indicator of student nurse's professional development and changing need for support. Nurse Educ Today. 2005;25(2):126-31. doi: 10.1016/j.nedt.2004.10.007. [PubMed: 15701538]. 